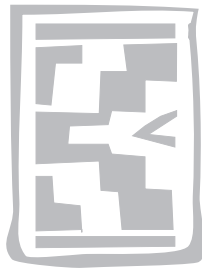

\title{
Evaluation of biochemical and ultrasonographic measurements as indicators of undernutrition in cattle
}

\author{
S. STRYDOM ${ }^{1}$, S. AGENÄS ${ }^{2}$, M.F. HEATH ${ }^{3}$, C.J.C. PHILLIPS ${ }^{4}$, G.H. RAUTENBACH ${ }^{1}$ \\ and P.N. THOMPSON ${ }^{1}$
}

\begin{abstract}
STRYDOM, S., AGENÄS, S., HEATH, M.F., PHILLIPS, C.J.C., RAUTENBACH, G.H. \& THOMPSON, P.N. 2008. Evaluation of biochemical and ultrasonographic measurements as indicators of undernutrition in cattle. Onderstepoort Journal of Veterinary Research, 75:207-213

Body condition scoring (BCS) gives an indication of the nutritional status of an animal and it is thus an invaluable management tool in domestic livestock systems. It is, however, subjective. This study aimed at identifying biochemical indicators which could be objectively used as an indicator of undernutrition in ruminants. Blood samples were collected from 50 cattle with BCS $\leq 1$ and from 50 cattle with BCS $\geq 2.5$, using a $0-5$ scale, and analysed for albumin, urea, creatinine, fructosamine, beta-hydroxybutyrate, non-esterified fatty acids, total serum protein and haematocrit. Rumpfat and ribfat thickness and marbling relative index were determined ultrasonographically in 15 of the low BCS group and 13 of the high BCS group. The laboratory measure with the best predictive ability for severe undernutrition was albumin, which correctly classified $94 \%$ of cattle, using a cut-off of $31.5 \mathrm{~g} / \mathrm{\ell}$. In contrast to a previous study, our study did not find the fructosamine:albumin ratio to be an accurate test to indicate undernutrition in cattle. Ultrasonic measurement of subcutaneous rumpfat and ribfat proved to reliably predict undernutrition, but may, however be impractical for routine use under most field conditions.
\end{abstract}

Keywords: Biochemical indicators, body condition scoring, cattle, ultrasonography, undernutrition

\section{INTRODUCTION}

Adequate nutrition is a fundamental requirement for the welfare of all domestic livestock. Undernutrition can be defined as insufficient nutrient supply and it

* Author to whom correspondence is to be directed. E-mail: gert.rautenbach@up.ac.za

1 Department of Production Animal Studies, Faculty of Veterinary Science, University of Pretoria, Private Bag X04, Onderstepoort, 0110 South Africa

2 Swedish University of Agricultural Sciences, Department of Animal Nutrition and Management, Kungsangen Research Centre, Uppsala, Sweden

3 Department of Veterinary Medicine, University of Cambridge, Madingley Road, Cambridge, CB3 OES, UK

4 Centre for Animal Welfare and Ethics, School of Veterinary Science, University of Queensland, Gatton 4343, QLD, Australia

Accepted for publication 28 May 2008-Editor may result in poor health and condition, the exhibition of abnormal behaviour and an inability to maintain body mass (Pearsall 1999; Stirrat 2003). The degree as well as the length of undernutrition will determine the effects on animal welfare.

Maintenance of acceptable body condition is essential as it directly affects both production and reproduction. Research indicates that body condition is a more reliable indicator of nutritional status than live mass (Eversole, Browne, Hall \& Dietz 2000). Body condition scoring is most commonly practised in domestic cattle and sheep but has proved to be subjective (Domecq, Skidmore, Lloyd \& Kaneene 1995). Thus the need for objective indices to monitor body condition and indicate undernutrition exists.

Blood chemistry changes might be used more objectively to indicate undernutrition and these changes 
differ between short- and long-term undernutrition. Long-term undernutrition can be divided into three phases. It starts with a rapid utilization of glycogen and protein which changes to a slower utilization of fat. Phase three is a period of increased protein utilization and the rapid mass loss during the later third phase becomes irreversible (Robbins 1994). In contrast, short-term starvation results in short-term negative energy and negative protein balances which may result in various blood chemistry changes. It is important to note that concurrent disease may also affect several blood parameters. A stable compound of glucose and protein (albumin or another serum protein), is referred to as fructosamine (Jensen, Peterson \& Houe 1993). Whereas blood glucose concentrations reflect the current situation, serum fructosamine reflects the average glucose concentration over the preceding two to three weeks (Armbruster 1987; Reist, Erdin, Von Euw, Tshuemperlin, Leuenberger, Chilliard, Hammon, Morel, Philipona, Zbinden, Kuenzi \& Blum 2002). In a previous field study, the fructosamine:albumin ratio was found to have an apparently satisfactory sensitivity to discriminate between undernourished and adequately nourished cattle (Agenäs, Heath, Nixon, Wilkinson \& Phillips 2006). However, the samples from the undernourished cattle had been stored for several years whereas fresh samples from adequately nourished cattle were used. This may have confounded the results as the effect of storage on fructosamine concentrations is uncertain. Further confirmatory work was therefore required. A study was thus performed on fresh samples from apparently healthy undernourished and adequately nourished animals to determine whether an effect on fructosamine:albumin ratio could still be demonstrated. A further objective was to identify other biochemical or ultrasonographic variables that could serve as a clinical test for undernutrition to be used in combination with body condition scoring.

\section{MATERIALS AND METHODS}

\section{Animal selection}

A total of 100 beef cattle were sampled. One group of 50 cattle had a body condition score $(B C S) \leq 1$, but were clinically healthy. These cattle were sampled from across South Africa, and were located with the help of private and state veterinarians. They had undergone chronic, severe undernutrition due to the seasonal depletion of natural grazing, combined with a financial inability of their owners to supplement the nutrition of their livestock. This undernourished group consisted of cross breeds of both sexes, ranging from 1 to $>4$ years of age, and only one was 3 months pregnant. A control group of 50 non-pregnant female cattle, including 23 Bovelders and 27 Bonsmaras, belonging to the University of Pretoria, was adequately nourished and clinically healthy with a $B C S \geq 2.5$. Body condition scoring was done on a scale of $0-5$, to a precision of 0.5 , according to the system of Wildman, Jones, Wagner, Bowman \& Lesch (1982).

\section{Procedures}

A clinical examination was done on each individual animal prior to any further procedures to ensure that the animal was not evidently diseased. This included rectal temperature, pulse, respiration, thoracic auscultation, mucous membrane colour and rumen auscultation. Estimates of the animals' ages were obtained by means of teeth evaluation on farms where adequate record keeping was absent. Due to the absence of electronic scales in the majority of places that were visited, a weigh band was used to estimate body mass. Pregnancy status was determined by means of rectal palpation. Blood in two $4.5 \mathrm{ml}$ serum tubes and one or two $10 \mathrm{ml}$ tube(s) containing heparin was collected from either the jugular or tail vein of each animal. The following parameters were analysed on the collected blood samples: albumin, urea, creatinine, fructosamine, beta-hydroxybutyrate (BHB), non-esterified fatty acids (NEFA), total serum protein (TSP) and haematocrit. Globulin concentration was calculated by subtracting albumin from TSP, and the fructosamine:albumin ratio (FAR) and albumin:globulin ratio (AGR) were calculated.

\section{Ultrasound measurement of subcutaneous fat}

Ultrasound measurement of the rump and rib subcutaneous fat depth and marbling of the eye (longissimus) muscle was done on a random sample of 15 of the undernourished animals and 13 of the adequately nourished animals. The scanning was done by trained staff from the ARC-Animal Improvement Institute, Irene, South Africa, using a Pie 100 ultrasound scanner with a Phantom probe (Philips, The Netherlands). For rumpfat thickness the transducer was aligned directly between the tuber coxae and tuber ischiadicum. The marbling relative index was derived from each animal's deviation from the expected relationship $\left(R^{2}=0.61\right)$ between marbling (intramuscular fat \%) and ribfat thickness (ARC 2006). Thus at a specific ribfat thickness, a certain level of marbling was expected in the eye muscle; if an animal showed more marbling than this, a higher index (>100) was obtained. 


\section{Data analysis}

The relationship between albumin, globulin, BCS and fructosamine was assessed using multiple regression. Mann-Whitney U-tests were used to compare medians of the various outcome variables between the adequately nourished and undernourished groups. For those biochemical and ultrasonographic measures that differed significantly between the two groups, receiver operating characteristic (ROC) analysis was used to compare their usefulness in discriminating between adequately nourished and undernourished animals (Greiner, Pfeiffer \& Smith 2000). The global performance of each measure in predicting undernutrition was calculated as the area under the ROC (sensitivity vs. 1-specificity) curve (AUC). Exact binomial confidence intervals were calculated for each AUC, and the AUCs were compared between measures. "Reference ranges" for each measure were calculated as the 2.5-97.5 percentile amongst the adequately nourished cattle. The sensitivity and specificity and their $95 \%$ binomial confidence intervals, of each measure for predicting undernutrition was calculated using the 2.5 percentile (or 97.5 percentile where applicable) as the cut-off value. The cut-off value for each variable which achieved $100 \%$ sensitivity and that which achieved $100 \%$ specificity were also calculated. Analyses were done using Stata 8.2 (StataCorp, College Station, TX, USA).

\section{RESULTS}

Median BCS in the undernourished cattle was 1 (range 0.5-1) and in the adequately nourished cattle it was 3.5 (range 2.5-4). The various clinical, ultrasonographic and biochemical measures in the two groups are shown in Table 1. The undernourished cattle had a lower body mass, pulse rate, rumpfat, ribfat, marbling relative index, creatinine, albumin, fructosamine, TSP, AGR and haematocrit, and a higher FAR and globulin than the adequately nourished cattle.

For both groups combined, albumin and globulin were both significantly associated with fructosamine ( $P<0.001$ and $P=0.003$, respectively), and together accounted for $45 \%$ of the variation in fructosamine levels. The relationship between fructosamine, albumin and globulin could be expressed as fructosamine $=68.1+3.51 \times$ albumin $+1.20 \times$ globulin . This is consistent with the fact that fructosamine is a coumpound of glucose and protein and therefore that fructosamine levels are correlated with protein levels. When adjusted for albumin and globulin, there was no significant linear association between BCS and fructosamine.

The AUC of the ROC curves for those variables that differed between the undernourished and adequately nourished groups are shown in Table 2 . Of the biochemical measures, albumin was the single best

TABLE 1 Clinical, ultrasound and biochemical variables in adequately nourished and undernourished cattle: descriptive statistics and comparison between groups

\begin{tabular}{|c|c|c|c|}
\hline Variable & $\begin{array}{l}\text { Adequately nourished cattle } \\
{\left[\text { Median }\left(\mathbf{I Q R}^{1}\right)\right]}\end{array}$ & $\begin{array}{l}\text { Undernourished cattle } \\
{\left[\text { Median }\left(I^{1} R^{1}\right)\right]}\end{array}$ & $P^{2}$ \\
\hline Rectal temperature $\left({ }^{\circ} \mathrm{C}\right)$ & $38.3(38.0,38.7)$ & $38.6(38.3,38.8)$ & 0.067 \\
\hline Pulse (beats/min) & $80(72,91)$ & $72(54,84)$ & 0.010 \\
\hline Respiration (breaths/min) & $28(24,32)$ & $24(18,32)$ & 0.211 \\
\hline Mass $(\mathrm{kg})$ & $445(355,527)$ & $265(238,310)$ & $<0.001$ \\
\hline Rumpfat thickness (mm) & $5.1(5.1,5.7)$ & $2.5(2.5,3.2)$ & $<0.001$ \\
\hline Ribfat thickness (mm) & $5.7(4.75,5.7)$ & $2.5(2.5,3.2)$ & $<0.001$ \\
\hline Marbling relative index & $69(62,72)$ & $51(48,55)$ & $<0.001$ \\
\hline $\mathrm{BHB}(\mathrm{mmol} / \ell)$ & $1.04(0.91,1.23)$ & $0.87(0.72,1.40)$ & 0.929 \\
\hline NEFA (mmol/l) & $0.125(0.078,0.210)$ & $0.126(0.058,0.351)$ & 0.662 \\
\hline Albumin $(g / \ell)$ & $36.4(34.9,38.4)$ & $28.4(24.5,30.8)$ & $<0.001$ \\
\hline Urea $(\mathrm{mmol} / \mathrm{l})$ & $2.95(1.70,5.05)$ & $3.30(2.10,4.84)$ & 0.869 \\
\hline Creatinine $(\mu \mathrm{mol} / \ell)$ & $135(120,145)$ & $113(101,129)$ & $<0.001$ \\
\hline Fructosamine $(\mu \mathrm{mol} / \ell)$ & $237(225,251)$ & $207(191,221)$ & $<0.001$ \\
\hline Fructosamine:albumin ratio & $6.35(6.15,6.83)$ & $7.36(6.78,8.28)$ & $<0.001$ \\
\hline $\mathrm{Ht}(\ell / \ell \times 100)$ & $39(35,42)$ & $29(26,32)$ & $<0.001$ \\
\hline $\mathrm{TSP}(\mathrm{g} / \mathrm{l})$ & $7.0(7.0,7.3)$ & $6.7(6.2,7.0)$ & $<0.001$ \\
\hline Globulin $(g / \ell)$ & $34.9(32.1,38.7)$ & $38.6(33.7,41.4)$ & 0.030 \\
\hline Albumin:globulin ratio & $1.01(0.93,1.19)$ & $0.76(0.61,0.88)$ & $<0.001$ \\
\hline
\end{tabular}

Interquartile range

$2 \quad P$-value for Mann-Whitney $U$ test for difference between medians 
Biochemical and ultrasonographic measurements as indicators of undernutrition in cattle

TABLE 2 Area under the receiver operating characteristic $(R O C)$ curve for all the variables where there was a significant difference in medians between undernourished and adequately nourished cattle

\begin{tabular}{|l|l|l|}
\hline Variable & $\begin{array}{l}\text { ROC } \\
\text { AUC }\end{array}$ & $95 \%$ confidence interval (AUC) \\
\hline Rectal Temp $\left({ }^{\circ} \mathrm{C}\right)$ & 0.606 & $0.507,0.706$ \\
Pulse $($ beats $/ \mathrm{min})$ & 0.650 & $0.544,0.740$ \\
Mass $(\mathrm{kg})$ & 0.950 & $0.886,0.983$ \\
Rumpfat thickness $(\mathrm{mm})$ & 1.000 & $0.877,1.000$ \\
Ribfat thickness $(\mathrm{mm})$ & 1.000 & $0.877,1.000$ \\
Marbling relative index & 0.975 & $0.810,0.999$ \\
Albumin $(\mathrm{g} / \mathrm{\ell})$ & 0.985 & $0.930,0.998$ \\
Creatinine $(\mu \mathrm{mol} / \ell)$ & 0.767 & $0.675,0.848$ \\
Fructosamine $(\mu \mathrm{mol} / \ell)$ & 0.850 & $0.762,0.913$ \\
Fructosamine:albumin ratio & 0.808 & $0.717,0.880$ \\
Ht $(\ell / \ell \times 100)$ & 0.952 & $0.875,0.986$ \\
TSP $(\mathrm{g} / \ell)$ & 0.745 & $0.636,0.838$ \\
Globulin $(\mathrm{g} / \ell)$ & 0.644 & $0.530,0.750$ \\
Albumin:globulin ratio & 0.923 & $0.842,0.972$ \\
\hline
\end{tabular}

TABLE 3 Reference ranges for albumin, fructosamine and fructosamine:albumin ratio calculated from the adequately nourished cattle, and sensitivity and specificity of various cutpoints for detecting undernourished cattle

\begin{tabular}{|c|c|c|c|c|c|c|}
\hline Variable & $\begin{array}{l}\text { Reference range } \\
\text { (2.5-97.5 percentile) }\end{array}$ & Cut-off & $\begin{array}{l}\text { Sensitivity } \\
(\%)\end{array}$ & $\begin{array}{l}95 \% \text { C.I.* } \\
\text { (Se) }\end{array}$ & $\begin{array}{l}\text { Specificity } \\
(\%)\end{array}$ & $\begin{array}{l}95 \% \text { C.I. } \\
\text { (Sp) }\end{array}$ \\
\hline Albumin $(g / \ell)$ & $31.5-41.0$ & $\begin{array}{l}\leq 35.9 \\
\leq 31.5 \\
\leq 31.1\end{array}$ & $\begin{array}{l}100 \\
90 \\
86\end{array}$ & $\begin{array}{l}94,100 \\
78,97 \\
73,94\end{array}$ & $\begin{array}{l}58 \\
98 \\
100\end{array}$ & $\begin{array}{l}43,72 \\
89,99.9 \\
94,100\end{array}$ \\
\hline Fructosamine $(\mu \mathrm{mol} / \ell)$ & $204.6-283.8$ & $\begin{array}{l}\leq 269.3 \\
\leq 204.6 \\
\leq 203.6\end{array}$ & $\begin{array}{l}100 \\
47 \\
47\end{array}$ & $\begin{array}{l}94,100 \\
33,62 \\
33,62\end{array}$ & $\begin{array}{l}10 \\
98 \\
100\end{array}$ & $\begin{array}{l}3.3,22 \\
89,99.9 \\
94,100\end{array}$ \\
\hline Fructosamine:albumin ratio & $5.71-8.25$ & $\begin{array}{l}\geq 5.86 \\
\geq 8.25 \\
\geq 8.29\end{array}$ & $\begin{array}{l}100 \\
27 \\
24\end{array}$ & $\begin{array}{l}94,100 \\
15,41 \\
13,39\end{array}$ & $\begin{array}{l}8 \\
98 \\
100\end{array}$ & $\begin{array}{l}2,19 \\
89,99.9 \\
94,100\end{array}$ \\
\hline
\end{tabular}

* Confidence interval

predictor of undernutrition (AUC $=0.985$ ), and was significantly better than fructosamine $(P=0.0004)$ and than FAR $(P<0.0001)$. The AUCs for fructosamine and FAR did not differ significantly $(P=0.53)$. The overall performance of selected variables is shown using their ROC curves in Fig. 1. The closer a curve comes to the top left-hand corner of the graph (i.e. sensitivity $=$ specificity $=100 \%$ ), the better its overall ability to discriminate between the two groups. In this dataset, body mass and haematocrit were also good predictors of undernutrition (AUC = 0.950 and 0.952 , respectively), and were not significantly different from albumin $(P=0.13$ and 0.15 , respectively). The ultrasonographic measures of rumpfat and ribfat thickness each perfectly predicted undernutrition $(A \cup C=1.00)$. At cut-off, values of $3.8 \mathrm{~mm}$ and $3.2 \mathrm{~mm}$, respectively, they were both $100 \%$ sensitive and specific. The marbling relative index did not perfectly predict undernutrition, but its
AUC (0.975) was not significantly different from that of the other two ultrasound measures $(P=0.27)$.

The sensitivity and specificity of albumin, fructosamine and FAR for predicting undernutrition, using various cut-off values, are shown in Table 3 . The greatest proportion of cattle correctly classified (94\%) using albumin as an indicator was achieved using the lower limit of its reference range $(31.5 \mathrm{~g} / \ell)$. Using fructosamine, a maximum of $79.8 \%$ of animals were correctly classified (at a cut-off of $222 \mu \mathrm{mol} / \ell$ ) and using FAR a maximum of $74.8 \%$ of animals were correctly classified (at a cut-off of 6.94 ).

\section{DISCUSSION}

In terms of the Animal Protection Act, No. 71 of 1962 of South Africa, section 2(1)c it is an offence to unnecessarily starve, underfeed, deny water or food 
S. STRYDOM et al.
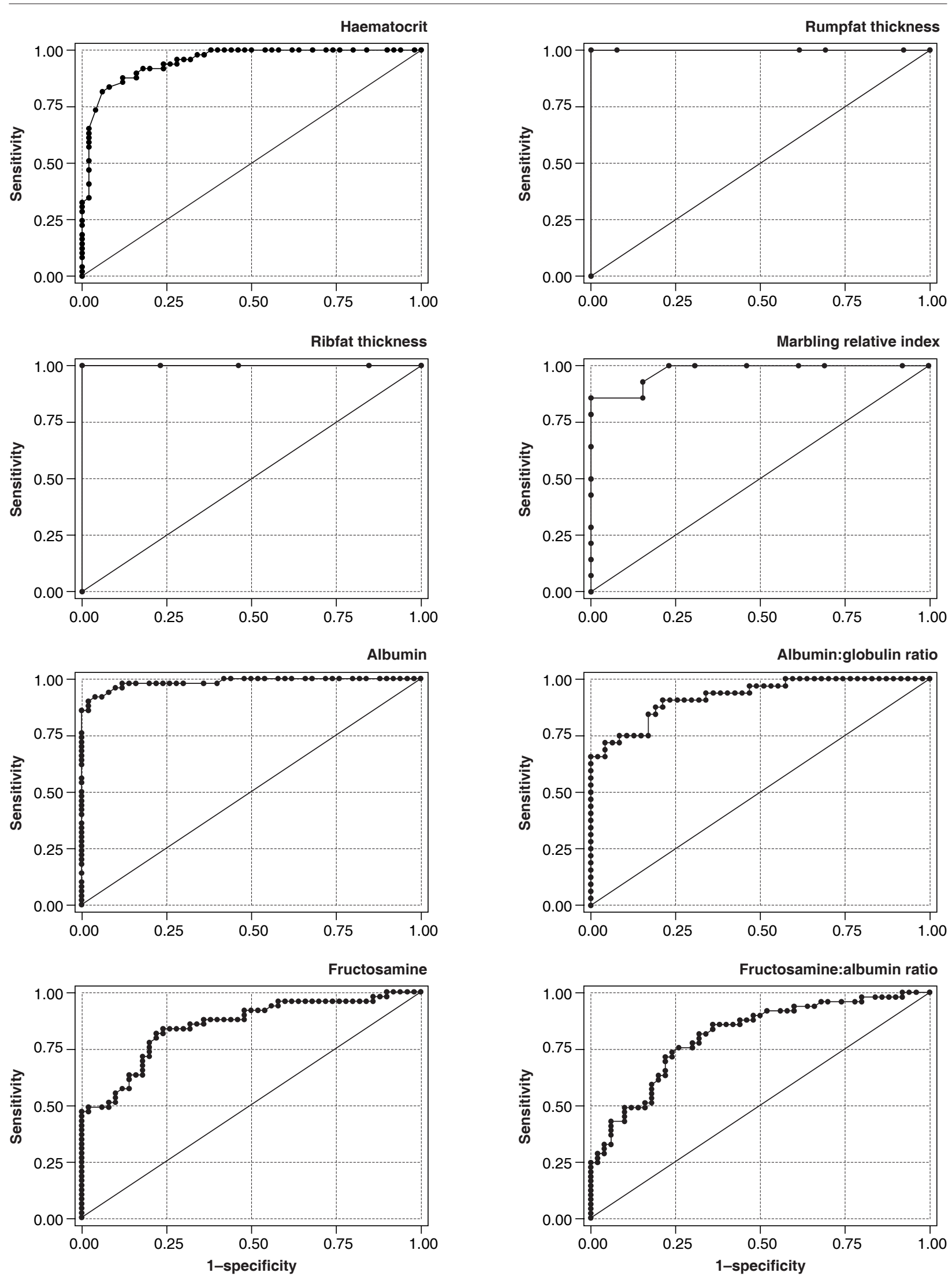

FIG. 1 Receiver operating characteristic (ROC) curves for the discrimination between undernourished $(B C S \leq 1)$ and adequately nourished $(\mathrm{BCS} \geq 2.5)$ cattle, using various clinical, biochemical and ultrasonographic measures 
to any animal. It may, however, be problematic to try to prove undernutrition based on a body condition score, as body condition scoring is a subjective evaluation of an animal's nutritional status. In this study, the problem of subjectivity was eliminated by using two separated BCS categories ( $\leq 1$ and $\geq 2.5$ ) and thereby not including marginal cases. Clinical examination was also used to try to ensure that the low BCS in the undernourished group were not due to other diseases.

In a previous study by Ping, Poland, Ottmar \& Landblom (2003) it was found that body condition scores can objectively be assigned to beef cattle by using ultrasound fat measurements in combination with age and body mass. Real-time ultrasound permits accurate measurements of subcutaneous fat thickness and the thickness of the subcutaneous back fat is also an accurate predictor of total fat and thus body condition in a variety of wild ruminants (Stephenson, Hundertmark, Schwartz \& Van Ballenberghe 1998; Stien, Irvine, Langvatn \& Ropstad 2003). In our study, as expected, cattle with low BCS had less body fat than cattle with high BCS. The undernourished group had significantly lower rumpfat and ribfat thickness as well as a lower marbling relative index. Ultrasonic measurements of rumpfat and ribfat were found to perfectly predict severe undernutrition (Fig. 1). It is unfortunately not always practical to use ultrasound measurements under field conditions. The ideal is therefore to identify a single biochemical indicator that could be used objectively to determine chronic (long-term) undernutrition in ruminants.

Blood chemistry changes are likely to differ between short-term and long-term undernutrition. Short-term negative energy balance in ruminants will result in elevated BHB and NEFA concentrations due to rapid mobilization of body tissue reserves (Hartmann \& Lascelles 1965; Baird, Heitzman \& Hibbitt 1972; McGuire, Bauman, Dwyer \& Cohick 1995; NdibuaIonji, Dehareng \& Godeau 1997; Reist et al. 2002; Agenäs, Dahlborn \& Holtenius 2003). In our study, there was no significant difference in BHB, NEFA or urea between the adequately nourished and the undernourished cattle. There does therefore not appear to be an increase in BHB and NEFA during chronic undernutrition. The undernourished cattle also had lower creatinine levels than the adequately nourished cattle, indicative of less muscle bulk. The data obtained in our study give little support to the use of fructosamine:albumin ratio as a sensitive test to confirm undernutrition. Since our study was performed on freshly taken samples, storage might have had an effect on the results obtained by Agenäs et al. (2006). However, the undernourished cattle in the earlier study may have been more extremely malnourished, since some mortalities occurred in that group (Agenäs, Heath \& Phillips, personal communication 2007). This raises the possibility that cattle in extremis may have a markedly changed fructosamine:albumin ratio, but this could not be confirmed in our study.

In this study, the biochemical measurement with the best predictive ability for undernutrition was albumin. There are, however, other causes of hypoalbuminaemia, including intestinal parasitism, chronic liver disease and renal disease, which may have been present and undetected in some animals in this study. Breed differences in serum albumin concentration have also been described (Shaffer, Roussel \& Koonce 1981; Boonprong, Sribhen, Choothesa, Parvizi \& Vajrabukka 2007), which may have had some influence on the results of this study, since the adequately nourished and undernourished groups were not standardised with respect to breed. The study of Agenäs et al. (2006), in which the breeds of the undernourished and adequately nourished cattle were similar, found serum albumin concentrations in the undernourished cattle to range from 20 to $37 \mathrm{~g} / \ell$ (Agenäs, Heath and Phillips, personal communication 2007), while the reference range for adequately nourished cattle was $25.0-44.4 \mathrm{~g} / \mathrm{\ell}$. In our study, serum albumin concentrations in the undernourished cattle ranged from 18.1 to $35.9 \mathrm{~g} / \ell$, and in the adequately nourished cattle from 31.3 to $41.1 \mathrm{~g} / \ell$. However, the exclusion of animals with BCS of 1.5 and 2 would have reduced the overlap in albumin concentration between the groups and thereby increased the sensitivity and specificity of albumin (and other measures) for predicting undernutrition. It is clear, however, that before critical levels can be utilised in the field, breed and other variables affecting albumin concentration in blood need to be better understood, which could be facilitated by a metaanalysis of literature data.

For the day to day management of ruminant nutrition, we still advise regular body condition scoring to be done by the same person(s) and making use of several pointers to decrease the subjectivity and increase the accuracy and consistency of the scoring process. These include training; the use of body condition scoring charts; ignoring the frame size of the animal; ignoring the stage of lactation of the animal; scoring appropriate body locations by looking at the lumbar vertebrae, tailhead and thurl and not looking at the ribs, shoulders or neck; viewing the 
animal from behind; rescoring a group of animalsimmediately after a scoring session, rescoring 10-20 animals and comparing the body condition scores with the original body condition scores to evaluate the consistency; and using a comfortable scoring range. A consistent individual will assign the same score greater than $90 \%$ of the time (Domecq 1997).

However, for a more objective assessment of a ruminant's nutritional status and welfare, particularly in cases of suspected severe undernutrition, the measurement of subcutaneous fat, combined with body condition scoring and blood variables such as albumin, creatinine and haematocrit should be considered. Due to trained staff and specialised ultrasound equipment often not being readily available, ultrasound measurement of subcutaneous fat should probably be reserved for cases where greater accuracy is required.

\section{ACKNOWLEDGEMENTS}

The ARC-Animal Improvement Institute, Irene is gratefully acknowledged for the ultrasound scanning and the analysis of the results.

\section{REFERENCES}

AGENÄS, S., DAHLBORN, K. \& HOLTENIUS, K. 2003. Changes in metabolism and milk production during and after feed deprivation in primiparous cows selected for different milk fat content. Livestock Production Science, 83:153-164.

AGENÄS, S., HEATH, M.F., NIXON, R.M., WILKINSON, J.M. \& PHILLIPS, C.J.C. 2006. Indicators of undernutrition in cattle. Animal Welfare, 15:149-160.

ARC 2006. Explanatory notes on the ARC-Animal Improvement Institute results from the real time ultrasound scanning. Irene: Agricultural Research Council.

ARMBRUSTER, D.A. 1987. Fructosamine: structure analysis and clinical usefulness. Clinical Chemistry, 33:2153-2163.

BAIRD, G.D., HEITZMAN, R.J. \& HIBBITT, K.G. 1972. Effects of starvation on intermediary metabolism in the lactating cow. A comparison with metabolic changes occurring during bovine ketosis. Biochemical Journal, 128:1311-1318.

BOONPRONG, S., SRIBHEN, C., CHOOTHESA, A., PARVIZI, N. \& VAJRABUKKA, C. 2007. Blood biochemical profiles of thai indigenous and Simmental $\times$ Brahman crossbred cattle in the Central Thailand. Journal of Veterinary Medicine A, 54: 62-65.

DOMECQ, J.J., SKIDMORE, A.L., LLOYD, J.W. \& KANEENE, J.B. 1995. Validation of body condition scores with ultrasound measurements of subcutaneous fat of dairy cows. Journal of Dairy Science, 78:2308-2323.
DOMECQ, J. 1997. Using body condition scores successfully. Michigan Dairy Review, Vol. 2, Nov. 1997. https://listserv. umd.edu/cgi-bin/wa?A2=ind $9801 \& \mathrm{~L}=$ dairynew\&P=298

EVERSOLE, D.E., BROWNE, M.F., HALL, J.B. \& DIETZ, R.E. 2000. Body condition scoring of beef cows. Virginia Cooperative Extension Beef Publication. http://www.ext.vt.edu/pubs/ beef/400-795/400-795.html.

GREINER, M., PFEIFFER, D. \& SMITH, R.D. 2000. Principles and practical application of the receiver-operating characteristic analysis for diagnostic tests. Preventive Veterinary Medicine, 45:23-41.

HARTMANN, P.E. \& LASCELLES, A.K. 1965. The effect of starvation on the uptake of the precursors of milk fat by the bovine mammary gland. Australian Journal of Biological Sciences, 18:1025-1034.

JENSEN, A.L., PETERSON, M.B. \& HOUE, H. 1993. Determination of the fructosamine concentration in bovine serum samples. Journal of Veterinary Medicine A, 40:111- 117.

MCGUIRE, M.A., BAUMAN, D.E., DWYER, D.A. \& COHICK, W.S. 1995. Nutritional modulation of the somatotropin/insulin-like growth factor system: response to feed deprivation in lactating cows. Journal of Nutrition, 125:493-502.

NDIBUALONJI, B.B., DEHARENG, D. \& GODEAU, J.M. 1997. Effects of starvation on plasma amino acids, urea and glucose in dairy cows. Annales De Zootechnie, 46:163-174.

PEARSALL, J. (Ed.) 1999. The concise Oxford dictionary, $10^{\text {th }}$ ed. Oxford: Oxford University Press.

PING, T., POLAND, C., OTTMAR, G. \& LANDBLOM, D. 2003. Can ultrasound measurements be effectively used to assign body condition scores in beef cattle? Dickinson Research Extension Center Annual Report-Grassland Section, North Dakota State University.

REIST, M., ERDIN, D., VON EUW, D., TSHUEMPERLIN, K., LEUENBERGER, H., CHILLIARD, Y., HAMMON, H.M., MOREL, C., PHILIPONA, C., ZBINDEN, Y., KUENZI, N. \& BLUM, J.W. 2002. Estimation of energy balance at the individual and herd level using blood and milk traits in high-yielding diary cows. Journal of Dairy Science, 85:3314-3327.

ROBBINS, C.T. 1994. Wildlife feeding and nutrition, $2^{\text {nd }}$ ed. New York: Academic Press.

SHAFFER, L., ROUSSEL, J.D. \& KOONCE, K.L. 1981. Effects of age, temperature-season, and breed on blood characteristics of dairy cattle. Journal of Dairy Science, 64:62-70.

STEPHENSON, T.R., HUNDERTMARK, K.J., SCHWARTZ, C.C. \& VAN BALLENBERGHE, V. 1998. Predicting body fat and body mass in moose with ultrasonography. Canadian Journal of Zoology, 76:717-722.

STIEN, A., IRVINE, R.J., LANGVATN, R. \& ROPSTAD, E. 2003. Evaluation of ultrasound scanning as a method for measuring subcutaneous fat in Svalbard reindeer. Rangifer, 23:7173.

STIRRAT, S.C. 2003. Body condition and blood chemistry of agile wallabies (Macropus agilis) in the wet-dry tropics. Wildlife Research, 30:59-67.

WILDMAN, E.E., JONES, G.M., WAGNER, P.E., BOWMAN, R.L. \& LESCH, T.N. 1982. A dairy cow body condition scoring system and its relationship to selected production characteristics. Journal of Dairy Science, 65:495-501. 